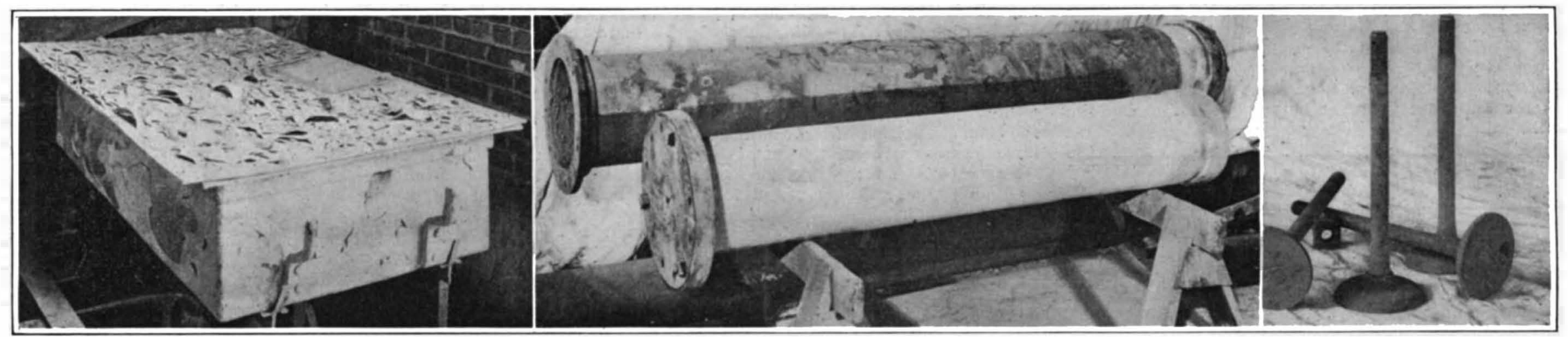

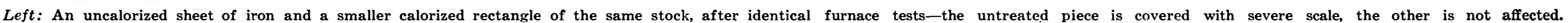
Center: Calorized (front) and uncalorized (rear) retorts after equal service. Right: Diesel-engine valves, a fair sample of the sort of thing that may profitably be calorized

Several exhibits designed to show the immunity to rusting under severe heat conferred by the new process of "calorizing"

\title{
Preventing Rust at High Temperatures
}

\section{Aluminum-Coated Metals That Will Go to the Melting Point Without Formation of Scale \\ By Robert June}

THE problem of devising means of protecting metals the axidation at high temperatures has occupied years. The remarkable industrial developments of the past few years, partic ing processes, have made this problem of pressing importance; and it has consequently received greatly increased consideration.

To say at the outset that this problem has largely been solved by the development of what is known as a calorizing process is to sum up the experiences and opinions of many metallurgists and industrial engineers who have encountered serious and at times seemingly unsurmountable difficulties in the rapid oxidation of metal parts at high temperatures.

tion of metal parts at high temperatures. aluminum, and the protective action is due to the oxide formed by the action of heat on the protecting alloy rather than to any electrolytic relations between the aluminum and the base. The product is distin guished from that of other processes such as sherardizing, hot galvanizing, etc., in that these are intended primarily to give protection against oxidation at ordinary temperatures, or corrosion, as it is frequently called, while the calorizing process is intended primarily to proter mperatures. Practically all metals suitable for structural work, with the exception of those in the platinum group, began to oxidize at quite low temperatures; on the Centigrade scale, steel at about 370 degrees, copper at 360 , nickel at 660, nickel-steel (58 per cent nickel) at 530, chrome-nickel (10 per cent chromium) at 650 , German silver at 530, and aluminum-bronze (9.2 per cent aluminum) at 600 . As a matter of fact most of these metals or alloys may be rum at a higher temperathese metals or allo: ture than that indicated before serious disintegration
sets in, but none of them has a very short life at sets in, but none of them
or above a full red heat.

or above a full red heat.
It is well known that an aluminum wire heated by an electric current above its melting point will stil maintain its shape due to the tough and resistant oxide of aluminum formed on its surface. It is this oxide which is the basis of the oxidationresisting properties of calorized metal. It ed metal. It is necessary, however, to have sufficien aluminum present to form a continuous coating of $\mathrm{Al}_{2} \mathrm{O}_{3}$ over the whole surface.
Experiment has shown that this requires, Experiment has shown that this requires,
in the case of iron alloys, at least 14 per in the case of iron

cent of aluminum. about 1911 in the electrical research laboratory at Schenectady, in the course of a series of experiments instituted to find a method of protecting electric heating elements. The process was later turned ments. The process was later turned
over to an independent corporation, as its over to an independent corporation, as its
industrial and commercial importance industrial and commercial importance
warranted its handling by a separate organization specializing in oxidation problems.

In treating metals by the calorizing process, they are first thoroughly cleaned by sand-blasting, then placed in a stationary or rotary retort in a reducing attionary or rotary retort in a reducing atfinely divided aluminuın and aluminum finely divided aluminum and aluminum
oxide. This treatment, conducted at a

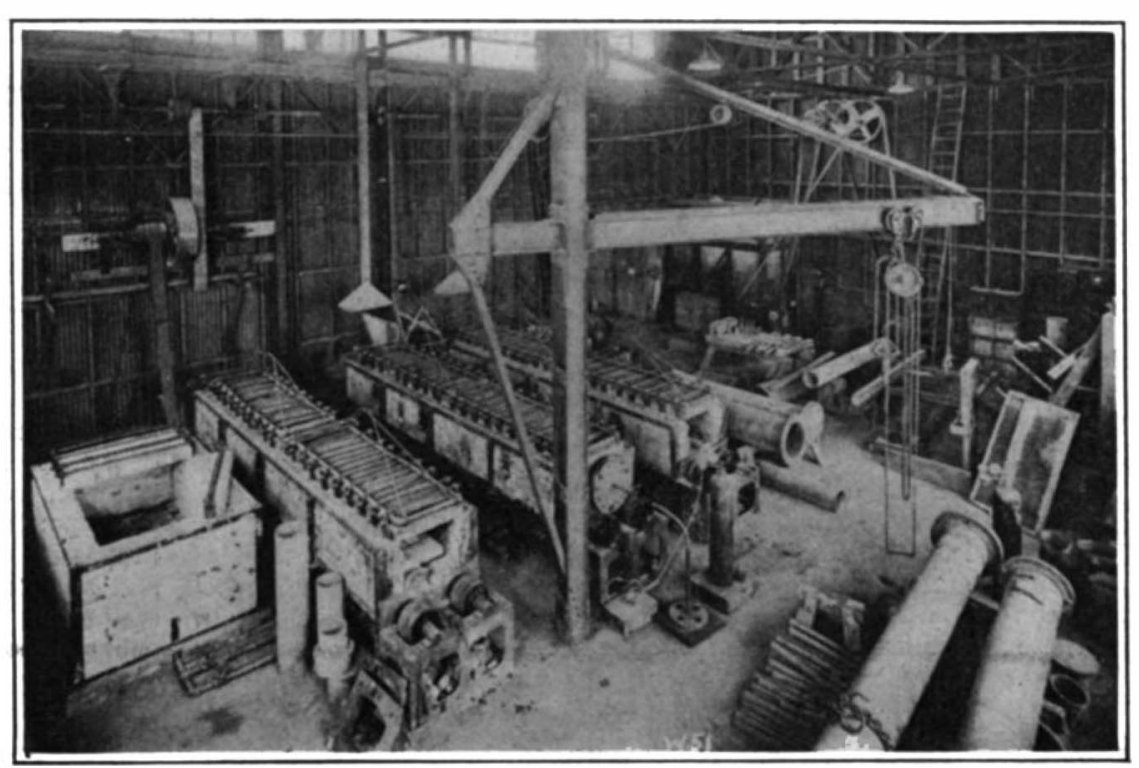

Retorts and furnaces in which the calorizing process is carried on vestigation of it was made in this application. In addition to mechanical tests, trial installations were made in all the different types of water-tube boilers. In making tests, calorized soot-blower units were placed in the hottest passes where the temperatures ranged from 1,800 to 2,500 degrees Fahrenheit. The need of blowers at these locations had long been recognized, but their application had been considered impracticable. Performance of the calorized units was watched with keen interest for months. In the end they proved that they fully met the hardest service conditions. There were no signs of scaling or disintegration from the long exposure to high temperatures. Thousands of successful installations have been made. and are now giving satisfaction in all types of water tube boilers. In addition to the matter of oxidation, many gases contain sulfur dioxide and carbon monoxide, which have an extremely deleterious effect on ordinary metal, while tests have shown that calorized metal is not affected by them in the percentages in which they occur in furnace gases.

The resistance of calorized iron to oxidation is a time-temperature function. It will resist oxidation up to its melting point for a short time, but to obtain a reasonable life, temperatures exceeding 900 to 1,000 degrees Centigrade should not be used unless the calorinzing treatment was unusually heary. The reason for this is evident when we consider that the diffusion of the aluminum into the iron is extremely rapid at high temperatures. It is about five times as fast at 1,300 as at 110 degrees Centigrade, which would cut the life to one-fifth when used at the higher temperature. By using thin sections and a heavy coating, however, steel may be calorized to stand the higher temperature for months.

Although tests show that the mechanical properties of the steel are not injured by calorizing, it must be pointed out that the rich aluminum alloy which forms the protective coatings is very hard; any bending or mechanical working should be done as far as possible before calorizing. If it must be done afterwards, the piece should be first heated to redness. Calorized metal cannot be hammered or bent cold, but at a bright red heat can be bent without affecting its resistance to oxidation. However, calorized metal is capable of withstanding all ordinary handling without destruction of the alloy or calorized portion.

Calorizing has been put to a great variety of uses including its application to retorts, carbonizing and annealing boxes, pyrometer tubes, furnace castings, tubes for preheating air, flue lining, pipe for conveying molten glass, torch nozzles, blast furnace tuyeres, oil crackers, sootblower units, lead pots, valve and piston heads for Diesel engines, preheating coils for oil burners, hot bulbs for oil engines, etc. Calorization has been successfully applied to carbonizing and annealing boxes and a variety of heat treating equipment of this nature, the treatment prolonging the life from three to thirty times.

It is entirely feasible to make up calorized coils of pipe in a wide variety of (Continued on page 412) 


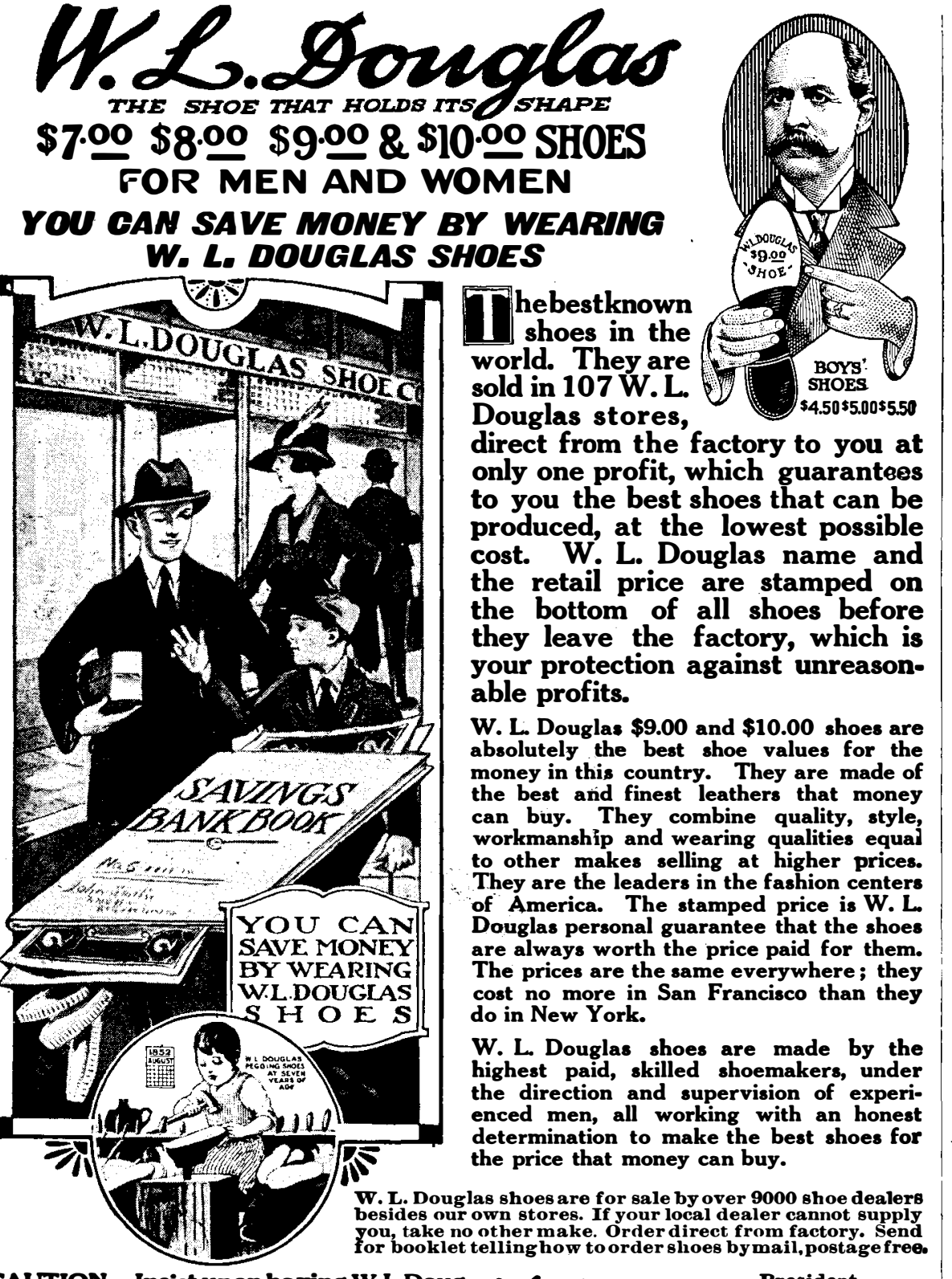

CAUTION. - Insist upon having W.L.Doug-
las shoes. The name and price is plainly
stamped on the sole. Be careful to see
that it has not been changed or mutilated. that it has not been changed or mutilated.

\section{R E L A T I V I T Y}

The Special and the General Theory

By Professor Albert Einstein, Ph.D. LL.D.

Translated by Professor Robert W. Lawson, M.Sc.

THE Einstein law has been accepted by astronomers and physicists 1 as an epoch-making discovery. Up to the present Newton's law of gravitation has been universally accepted, but the new theory goes farther, and, apart from supplying the laws of Newtonian mechanics when certain approximations are made, it enables us to predict the exact course of all motions resulting from gravitation. In this book, which is a popular exposition written for the average reader, Professor Einstein explains his famous theory which has so excited the scientific world. This volume is intended primarily for those readers who, though interested in the trend of modern theory, are not conversant with the mathematical analysis used in theoretical physics. The author's aim has been to give an exact insight into the theory of relativity, and to present the main ideas in the clearest and simplest form. $\mathrm{He}$ has succeeded admirably, and those who desire an authoritative and understandable explanation of the Einstein theory will find it between the covers of this book.

\section{Price $\$ 2.50$, by Mail $\$ 2.58$}

$$
\text { For Sale by }
$$

SCIENTIFIC AMERICAN PUBLISHING CO. 233 Broadway
The Aerial Cruiser

Continued from page 409)

etc., and the sleeping accommodation conMeals are exhaust from the cookers

Streamlining and Efficiency

The most careful attention has been given to the design of the cars with the result that a great increase in aerodynamical efficiency has been obtained over the cars of R-33 class airships. By making all the cars of the best known streamline shape, the head resistance as compared with R-33 class cars has been reduced by over 60 per cent, and the utilization of the fine nose of the control car as an observation station for the use of the navigating officer gives exceptional facilities for groundwork, which are not obtained in other designs.

The cars themselves are designed on a principle which enables the weight, as compared with similar cars of R-33 type to be cut down by over 50 per cent with greater strength and rigidity of structure. More roomy cars are therefore provided, the beam of the control car being eight feet as against a maximum of six feet on R-33 class

\section{Mooring}

Costly experience in the early days of the Zeppelin experiments showed that the greatest peril to the airship occurred when it came near the earth, and several years ago the ScIEnTIFIC AMERICAN pointed out that some form of mooring post to which the dirigible could make fast was necessary if landing disasters were to be avoided. The problem has been very ably worked out in the Vickers mooring gear, and R-80 carries in her nose the neces. sary gear for sailing up to one of these posts and making fast. A covered gangway can be thrown across from the moored airship to the mooring post through which the passengers pass to elevators arranged within the post. Gas, oil and water pipes form a permanent part of the mooringpost equipment, and they are provided at their upper ends with suitable connections for supplying the airship.

Preventing Rust at High Temperature

(Continued from page 404)

shapes, lengths and sizes. Straight pipe $1 / 8$ inch to 18 inches diameter has been calorized in lengths up to 20 feet. There is no limit to the size of material which may be treated. Calorized steel is particularly adapted to pyrometer protection tubes because of the high temperature to which they are exposed. Not only is it cheaper than any of the chrome steel alloys which have at times been offered for this purpose, but it possesses other advantages.

Perhaps the largest and most easily developed field for calorizing lies in its application to the various pots, boxes, tubes, retorts, and special equipment employed in the many heat treating processes. A large quantity of the above mentioned articles have been successfully calorized, their average life being over eight times that of the uncalorized equipment, resulting in a great saving. A notable feature is that calorizing can be applied to any of this equipment without necessitating change in its design or construction.

Many furnaces, kilns, ovens and retorts employed in various manufacturing processes were originally made of iron or steel. This metal has a limited heat-resisting quality and was reduced to scrap in a short time. It was repeatedly replaced, its life being short because of the excessively high temperatures and the same performance continued indefinitely. As the price of the metals increased, the use of the other materials was considered by engineers in an effort to reduce costs. They built these furnaces from fire-brick and various refractory materials. In a great many instances these materials were used at a loss of
LEGAL NOTICES

\section{P A T E N T S}

IF YOU HAVE AN INVENTION 1 which you wish to patent you can Co. for advice in regard to the best way of obtaining protection. Please send sketches or a model of your invention and a description of the device, explaining its operation.

All communications are strictly confidential. Our vast practice, extending over a period of seventy years, enables us in many cases to advise in regard to patentability without any expense to the client. Our HandBook on Patents is sent free on request. This explains our methods,

terms, etc., in regard to Paten
Trade Marks, Foreign Patents, etc.

SCIENTIFIC AMERICAN contains Patent Office Notes. Decisions of
interest to inventorse and particulars of re-

MUNN \& CO., SOF PATENTS Woolworth Building. NEW YORK WASHINGTON, D. C.
Hobartific American Building, Bilding,
HAN FRANCISCO, CAL

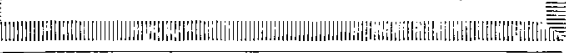

Annual Subscription Rates Scientific American Publications year American (established 1845) one $\$ 6.00$

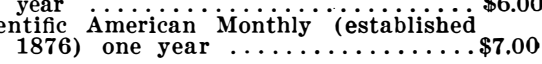
tage prepaid in United States and posses-
sions, Mexico, Cuba and Panama. Foreign Postage

Scientific American \$1.50 per year additional.
Scientific American Monthly $72 \mathrm{c}$ per year ad-

Canadian Postage
Scientific American 75c per year additional. tional. The combined subscription rates and rates to
foreign countries including Canada, will be
furnished upon application.

Remit by postal or express moncy order, bank
draft or clieck.

Classified Advertisements Advertising in this column is $\$ 1.00$ a line.
No less than four nor more than 12 lines
accepted. Count seven, words to the line. All $\frac{\text { orders must be accompanied by a remittance. }}{\text { AGENTS WANTED }}$ AGENTS- 40 -8100 weeklv; free samples, gold sign
letters; anyone can put on store windows; liberal offer
to general agents. Metallic Letter Co., 431X N. Clark Street, Chicago.
ALUMINUM SOLDER

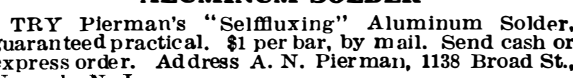
Newark, N. J.
BOILERS FOR SALE

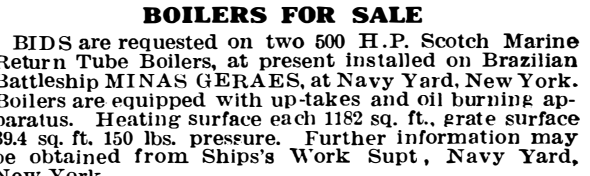
BUSINESS OPPORTUNITY SUBSTANTIAL manufacturing corporation wants
apable men to establish branch and manage salesmen capable men to establish branch and manage salesmen.
$\$ 300$ to $\$ 2000$ necessary
mill allow expenses to Balttmore as explained. Address, Mr. C
Eutaw St., Baltimore. Md.
HELP WANTED PATFNT Office Draftsman. State experience and
olary desired. Munn \& Co., 233 Broadway, New York WANTED
THE exclusive manufacturing rights of some ma-
chine, device, or article in the metal line patented or
otherwise, by one of the most completelv equipped manufactiring plants in Indiana. Address W. F. M.-
P. O. Box No. 263, Bedford, Indians.

Valuable Books of Instructionand Reference

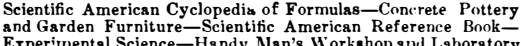
SCIENTFFIC AMERICAN PUBLISHING CO., Woolworth Bldg., New York

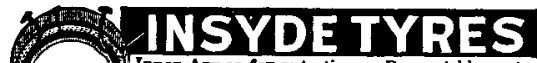

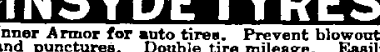
Send 10 cents coin or stamps for

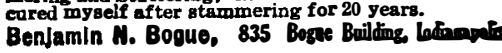




\section{PYORRHOCCIDF} for Pyorrhea prevention

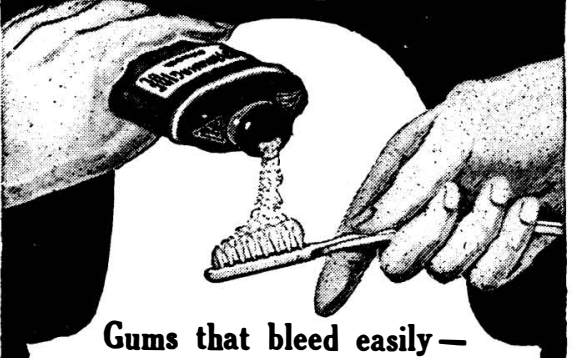

that are soft and sensitive-warn you that pyorrhea is developing. 'Loss of teeth will surely follow unless pyorrhea is checked or prevented. Dental clinics, devoted exclusively to pyorrhea research and oral pro phylaxis, have proved the specific value of Pyorrhocide Powder for restoring and maintaining gum health. It is prescribed by the den tal profession for pyorrhea treatment and prevention. It keeps the gums healthy and the teeth clean.

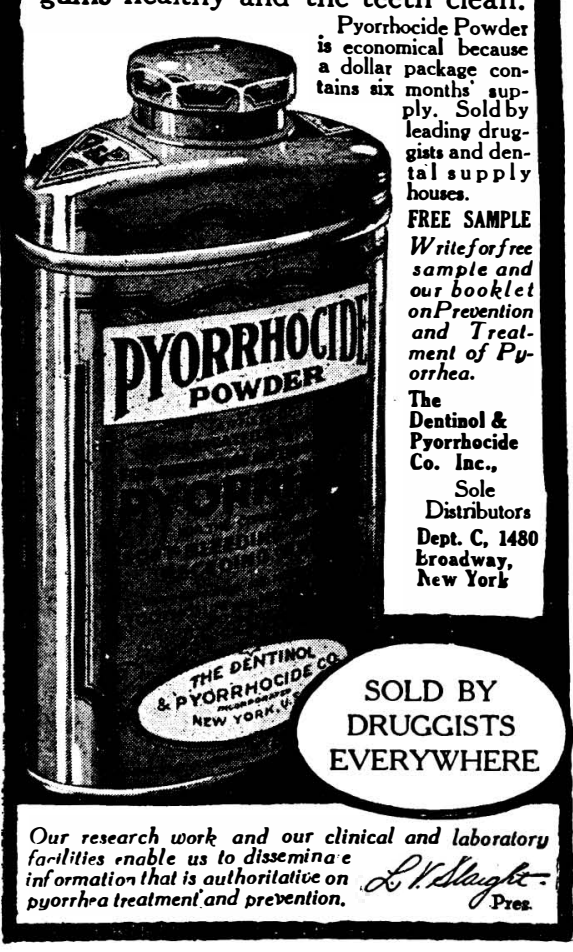

ORANGES From $_{\text {Free }}^{\text {AND GRUT }}$

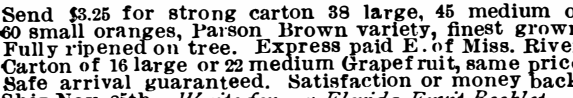
Ship Nov. 2 thth. Write for my Florida Fritit Booklet.
C. H. Voorhees, Box 405, So. Lake Weir, Florid 158 Gen upe Forelyn Stamps-Mexico War Is

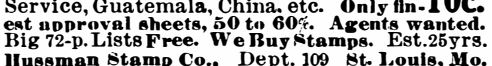

For Spot Cash mail false teeth, old and watches, old gold, silver, platinum, War bonds o
Stamps-anything, valuable.
Goods returned in 10 days if you're not ret satisfled Ohio Smelting and Refining Co., 234 Lennox Bldg., Cleveland, 0 .

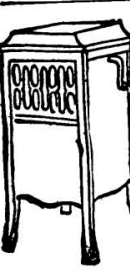

Cleartone Phonographs $\$ 4.00$ to $\$ 200.00$ Retail

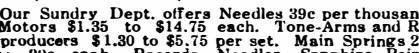
and Parts ait ressonable priceses. Sapphire Point

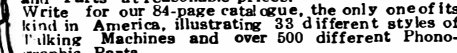

LCCKY 13 PHONOGRAPH COMPANY

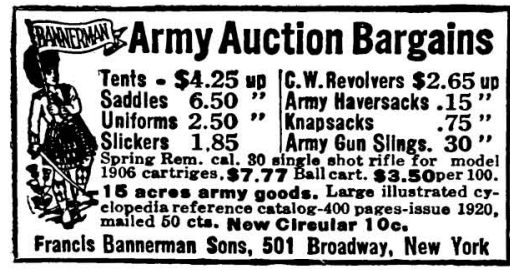

25 to 75 per cent efficiency, but were adopted because the repair costs on iron and steel were prohibitive. Calorizing can be applied to metal furnace lining, baffle plates, etc., the cost of these calorized plates per unit of service being in a great many cases much less than that of refractory materials. There is an unlimited field for calorizing as applied to equipment of this nature.

There are many possible applications of calorized metal which have not been considered, for the reason that only within the last six months has calorizing been available to the commercial world. It is impossible to enumerate or describe in detail the great number of applications. Every plant presents its individual problem and it is the object of the writer to illustrate several applications with the idea of suggesting to the engineer, metallurgist, and plant manager, possible applications to special equipment used in his particular process of manufacture.

\section{A Pocket Machine Gun}

(Continued from page 405)

obliged in his work to sit behind various machine guns in erosion, function, and ballistic tests for a matter of six months or more, and he was not impressed at the end of this time with the reliability of function of any machine gun at present used by civilized armies, examples of which we tested. Used under the most favorable conditions, in the hands of skilled mechanics, they all were made to look simply childish in certainty of function and endurance when compared to that other gas engine- the motor of the small car. A stoppage, a broken part, a jamone of the three would occur with the most reliable machine gun of them all, the Browning, about every 1,000 rounds firell. One thousand impulses of any given cylinder in the auto motor will, in high gear, run the little car something like a mile, and a hundred-mile run means that each cylinder has fired a hundred times as many "shots" as the machine gun averages between bits of trouble. Not even the most pessimistic of ca owners will deny that the motor will run the car a hund

stop, jam, or break.

I cheerfully admit the difference in conditions, such as the far greater presspeed of the machine gun and the higher there is not enough difference in conditions to justify the wide difference in reliability between the two types of gas engines. Possibly, therefore, the decision of the latest entrants into the machine gun market to use lubrication is based on sound judgment. There is also the possibility that they are making virtue out of a necessity.

The new gun is arranged to fire any pistol cartridge, the change necessary being merely in barrel, magazine and bolt-head. Special cartridges containing buckshot will also function the gun, and make for close-up work a tremendously effective weapon

The writer, after firing the gun severa hundred rounds, would class it as the equal of a score of average policemen firing as the average policeman fires, prowere fred by a far easier to train one man to become expert with the gun than it is to raise the shooting of twenty policemen to the expert stage with their pistols.

There would be no trouble whatever for one man firing the gun to sweep a street clear from curb to curb, but after all, its greatest strength lies in its moral effect. Killing many of the common American sort of mob is unfortunate un less the right ones can be selected for the slaughter. Mobs as a rule are comthe slaughter. Mobs as a rule are composed of ten per cent vicious (the leaders), and ninety per cent fools. Where out bloodshed is usually desirable. It would be a most vicious and determined

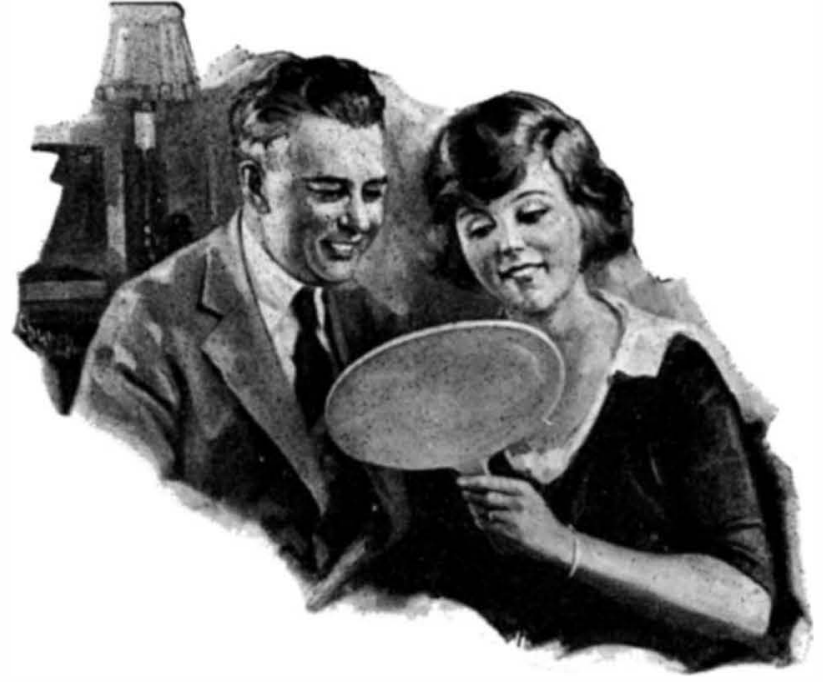

Make This Test

\section{Watch how your teeth respond}

This ten-day test has shown to millions the way to whiter, safer teeth. It is a free test-you should make it. No Pepsodent does for teeth.
Per do what

To end the film

The object is to fight the film, which dims the teeth and causes most tooth troubles. Dental science has worked years to do that

Film is that viscous coat you feel It clings to teeth, enters crevices and stays. The ordinary tooth paste does not combat it satisfactorily,

ing leaves much of it intact. It is the film-coat that discolors, not It holds food substance which ferments and forms acid. It holds the acid in contact with the teeth to cause decay.

\section{Five Much Desired Effects}

One ingredient of Pepsodent is pepsin. Another multiplies the starch digestant in the saliva to digest the starch deposits which cling and form acid.

It also multiplies the alkalinity of the saliva, to neutralize the acids which cause tooth decay. Two facthem keeps teeth so highly polished that film cannot easily adhere.

Pepsodent combines the best that Pepsodent combines the best that
modern science knows to combat the

great tooth destroyers. It has brought w era in teeth cleaning.

Watch it act

Send the coupon for a 10-Day Tube. Note how clean the teeth feel after using. Mark the absence of the viscous film. See how teeth whiten as the filmcoat disappears.

You will see several new effects, and the book we send will tell you what they mean. This is too important to forget. Cut out the coupon now.

\section{Pepsodent \\ The new-day dentifrice}

A scientific film combatant, now advised by leading dentists everywhere. Supplied in large tubes by all druggists

Cut out this coupon now

Note how clean the teeth feel after using. Mark the absence of the viscous film. See how teeth whiten as the film coat disappears. This has brought to millions a new era in teeth cleaning.

\section{0-Day Tube Free} THE PEPSODENT COMPANY, Dept. 917, 1104 S. Wabash Ave., Chicago, Ill. Mail 10-Day Tube of Pepsodent to 